\title{
Pengaruh Laba Bersih dan Debt to Equity Ratio terhadap Dividen pada PT. Adaro Energy Tbk 2010 - 2017
}

\author{
Septi Utami ${ }^{1}$, Nor Norisanti ${ }^{2}$, Faizal Mulya $Z^{3}$ \\ ${ }^{123}$ Fakultas Ilmu Administrasi dan Humaniora Universitas Muhammadiyah Sukabumi \\ Email : septiutami945@gmail.com
}

\begin{abstract}
The purpose of this study was to study the effect of net income and the Debt Ratio on Equity to Dividends at PT. Adaro Energy Tbk 2010-2017. The technique used in this study was purposive sampling. The population used in this study is the financial statements of PT. Adaro Energy Tbk, which is listed on the IDX. And the sample from financial statements is available for 32 periods (quarterly). The results of the determination coefficient test (R2) of 0.253 can be interpreted that the effect of Net Profit and Debt To Equity Ratio to Dividend is $25.3 \%$. The remaining $74.4 \%$ is influenced by other factors not explained in this study. Based on the multiple correlation coefficient test seen from the $R$ value of 0.503 , indicating that there is a moderate relationship between Net Profit and Debt To Equity Ratio with Dividends. Based on the F test the probability value sig. 0.015 $<0.05$ which means that together the value of Net Profit (X1) and Debt To Equity Ratio (X2) have a significant effect on dividends $(Y)$. Based on the test shows that Net Profit (X1) does not significantly influence dividend (Y), Debt To Equity Ratio (X2) does not significantly influence dividend (Y).
\end{abstract}

\section{Keywords : Net Profit, Debt to Equity Ratio, Dividen}

Abstrak

Tujuan dari penelitian ini yaitu untuk mengetahui seberapa besar pengaruh laba bersih dan Debt to Equality Ratio terhadap Dividen pada PT. Adaro Energy Tbk 2010-2017. Teknik yang digunakan pada penelitian ini dengan purposive sampling. Populasi yang digunakan dalam penelitian ini ialah data laporan keuangan PT. Adaro Energy Tbk yang terdaftar di BEI. Dan yang dijadikan sampel ialah laporan keuangan yang tersedia selama berturut-turut selama 32 periode (triwulan). Hasil dari penelitian uji koefisien determinasi $\left(\mathrm{R}^{2}\right)$ sebesar 0,253 dapat diartikan bahwa pengaruh Laba Bersih dan Debt To Equity Ratio terhadap Deviden sebesar 25,3\%. Sisanya sebesar 74,4\% dipengaruhi oleh faktor lainnya yang tidak dijelaskan dalam penelitian ini. Berdasarkan uji koefisien korelasi ganda dilihat dari nilai $\mathrm{R}$ sebesar 0,503 , menunjukkan bahwa terjadi hubungan yang sedang antara Laba Bersih dan Debt To Equity Ratio dengan Deviden. Berdasarkan uji F nilai probabilitas sig. $0,015<$ 0,05 yang berarti secara bersama-sama nilai Laba Bersih (X1) dan Debt To Equity Ratio (X2) berpengaruh secara signifikan terhadap Deviden (Y). Berdasarkan uji t menunjukkan bahwa Laba Bersih (X1) tidak berpengaruh secara signifikan terhadap Deviden (Y), Debt To Equity Ratio (X2) tidak berpengaruh secara signifikan terhadap Deviden (Y).

Kata Kunci : Laba Bersih, Debt to Equity Ratio, Dividen

(C) 2019 Jurnal Riset Inspirasi Manajemen dan Kewirausahaan

\section{PENDAHULUAN}

Di era globalisasi yang berkembang pesat ini mengaruskan perusahaan-perusahaan besar di indonesia saling berkompetisi khususnya perusahaan yang sudah go public. Banyak individual atau suatu kelompok yang sedang merambah bisnisnya tertarik pada dunia pertambangan. Potensi negara yang kaya akan sumber daya alam yang melimpah membuat perusahaan- perusahaan tertarik pada bisnis pertambangan. Sub sektor pertambangan yang terdaftar di BEI ialah perusahaa-perusahaan yang sudah siap menginvestasikan sahamnya dan melaporkan laporan keuanganya secara terbuka dalam periode atau triwulan tertentu.
Perusahaan Pertambangan yang sudah go public tentunya harus memiliki laporan keuangan yang terperinci. pelaporan keuangan ini juga menjadi dasar suatu pemegang saham atau perusahaan kedepannya dalam mengambil keputusan, baik itu berupa penilaian kinerja manajemen ataupun pembagian dividen kepada pemegang saham. Laporan keuangan berpengaruh terhadap minat calon pemegang saham, semakin efektif dan efesien terhadap kebijakan manajemennya untuk mempertahankan dan mengembangkan usahanya. Pemegang saham yang menanamkan dananya untuk mendapatkan keuntungan lebih yang disebut dividen.

Menurut Sutrisno (2012: 226), Dividen berupa laba yang dibagikan kepada pemegang saham. Dengan naiknya dividen dari waktu ke waktu dapat 
menjadikan pemegang saham percaya pada perusahaan tersebut. Jika perusahaan dapat membayarkan dividen dalam jumlah yang besar,maka dapat diasumsikan masyarakat atau pemegang saham bahwa perusahaan tersebut menguntungkan.

Faktor yang mempengaruhi pembagian dividen yang pertama ialah besarnya laba yang diperoleh perusahaan, Jika laba bersih mengalami peningkatan maka bisa diprediksikan bahwa dividen juga meningkat, dan sebaliknya penurunan dividen yang diterima menunjukkan kondisi perusahaan yang sedang tidak baik yaitu dengan penurunan laba yang diperoleh, bersumber dari penelitian terdahulu (Luluk Muhimatul Ifada dan Nia Kusumadewi : 2014).

Faktor lain dalam pembagian dividen ialah penggunaan hutang perusahaan. Peran hutang dalam perusahaan sangat membantu dalam peluasan bisnis, akan tetapi jika hutang yang digunakan melampaui batas maka ini akan berdampak buruk pada perusahaan. Debt To equity Ratio (DER) ialah salah satu rasio yang digunakan untuk melihat seberapa besar perusahaan dapat melunasi kewajibannya. Menurut Fahmi (2012:128) Debt To equity Ratio (DER) diartikan sebagai ukuran yang dipakai dalam menganalisis laporan keuangan untuk memperlihatkan besarnya jaminan yang tersedia untuk kreditor.

PT. Adaro Energy Tbk merupakan salah satu perusahaan pertambangan yang sudah go public dan menjadi pemasok terbesar antar lintas samudra dengan produksi tahunan mencapai 25 ton dan menjadi perusahaan yang berkomitmen untuk membayar dividen tiap tahunnya. Dari data yang diperoleh pada PT. Adaro Energy yang terdaftar di Bursa Efek Indonesia, terjadinya peningkatan hutang yang tidak seimbang dan kesulitan dalam menentukan seberapa banyak laba bersih yang akan dibagikan pada pemegang saham, dikarnakan dapat dilihat dari pembagian dividen setiap periode tidak stabil. Oleh sebab itu peneliti ingin mengetahui bagaimana "Pengaruh Laba Bersih dan Debt To Equity Ratio Terhadap Dividen Pada PT Adaro Energy Tbk 2010 - 2017.

\section{KAJIAN LITERATUR}

\section{Laba Bersih}

Menurut Henry Simamora (2013:46) dapat dijelaskan bahwa :

"Laba bersih yang berasal dari transaksi pendapatan, beban, keuntungan dan kerugian. Laba dihasilkan dari selisih antara sumber daya masuk (pendapatan dan keuntungan) dengan sumber daya keluar (beban dan kerugian) selama periode tertentu". Dengan kata lain, laba bersih dihasilkan dari pengurangan laba berjalan dengan beban lainnya termasuk pajak pada periode tersebut".
Laba bersih di definisikan sebagai laba yang diperoleh setelah dikurangkan dengan pajak. (Irham Fahmi, 2022:101).

Laba Bersih didapatkan dengan cara :

Laba Bersih = Pendapatan - Beban

\section{Debt to Equity Ratio}

Rasio yang digunakan untuk menilai hutang dengan ekuitas. Rasio dicari dengan cara membandingkan antar seluruh hutang. Termasuk utang lancar dengan seluruh ekuitas (Kasmir, 2012: $157)$.

Debt to Equity Ratio menurut Sutrisno (2012:218) dapat dijelaskan bahwa :

"merupakan imbangan antara hutang yang dimiliki perusahaan dengan modal sendiri.semakin tinggi rasio ini berarti modal sendiri semakin sedikit dibandingkan dengan hutangnya. Bagi perusahaan, sebaiknya besarnya hutang tidak boleh melebihi modal sendiri agar beban tetapnya tidak terlalu tinggi,artinya debt to equalitynya maksimal $100 \%$ ".

Debt To Equality didapatkan dengan cara :

$$
\text { DER }=\frac{\text { Total Hutang }}{\text { Total Modal }}
$$

\section{Dividen}

Dividen menurut Toto Prihadi (2010:231) dapat dijelaskan bahwa :

"merupakan bagian laba bersih yang dibagikan kepada pemegang saham biasa. Perusahaan secara sadar hanya akan membagikan beberapa persen dari laba bersih yang diperoleh sebagai dividen. Apabila tidak dibagi maka laba tersebut akan masuk ke dalam saldo laba dan dana cadangan”.

Menurut Rudianto (2012:290) “merupakan pembayaran tunai yang dibayarkan oleh perseroan kepada pemegang saham".

Dividend Payout Ratio (DPR) menurut Sundjaja dan Inge Berlian (2009 : 391) dapat dijelaskan bahwa :

"mencerminkan kemampuan perusahaan dalam memenuhi seluruh kewajibannya, peningkatan hutang akan mempengaruhi besar kecilnya laba bersih yang tersedia bagi para pemegang saham karena kewajiban tersebut telah diprioritaskan dari pada pembagian dividen".

Dividend Payout Ratio didapatkan dengan cara :

DPR $=\frac{\text { Dividen Perlembar Saham }}{\text { Laba bersih perlembar aham }}$ 
Hipotesis

$\mathrm{H}_{1}$ : Terdapat Pengaruh positif dan signifikan laba bersih terhadap dividen perusahaan

$\mathrm{H}_{2}$ : Terdapat pengaruh positif dan signifikan debt to equity ratio terhadap dividen perusahaan

$\mathrm{H}_{3}$ : Terdapat pengaruh positif dan signifikan laba bersih dan debt to equity ratio terhadap dividen perusahaan.

\section{METODE PENELITIAN}

Penelitian ini menggunakan metode kuantitatif untuk perolehan data dan asosiatif untuk mengukur seberapa besar pengaruh laba bersih dan Debt to Equality Ratio terhadap dividen dengan menggunakan pendekatan deskriptif untuk mengatahui dari masing masing nilai variabel mandiri pada setiap variabel yang akan diteliti. Populasi pada penelitian ini yaitu data laporan keuangan PT. Adaro Energy Tbk yang terdaftar di BEI. Sampel dalam penelitian ini ialah laporan keuangan yang tersedia selama berturut-turut selama 32 periode (triwulan) dengan teknik sampling purposive.

\section{Teknik Pengumpulan Data}

Data yang digunakan pada penelitian ini yaitu menggunakan data sekunder. Data sekunder ialah data yang bersumber secara tidak langsung yang diperoleh dari media berupa dokumen. Pada penelitian ini data PT. Adaro Energy Tbk periode 2010-2017 diperoleh dari situs www.idx.com dan www.idnfinancials.com. sumber data lainnya diperoleh dari perpusatkaan.

\section{Teknik Analisa Data}

Teknik analisis yang digunakan pada penelitian ini adalah menggunakan analisis data regresi linier berganda termasuk dengan uji koefisien determinasi, koefisien korelasi dan uji secara parsial menggunakan uji t serta uji f dengan bantuan program SPSS (Statistic Product \& Services Solution) versi 24.

\section{HASIL PENELITIAN DAN PEMBAHASAN}

\section{Regresi Linier Berganda}

Regresi ganda digunakan oleh peneliti untuk meramalkan bagaimana keadaan (naik turunnya) variabel dependen, bila dua atau lebih variabel independen sebagai faktor prediktor dimanipulasi (di naik turunkan nilainya) (Sugiyono, 2012:277).

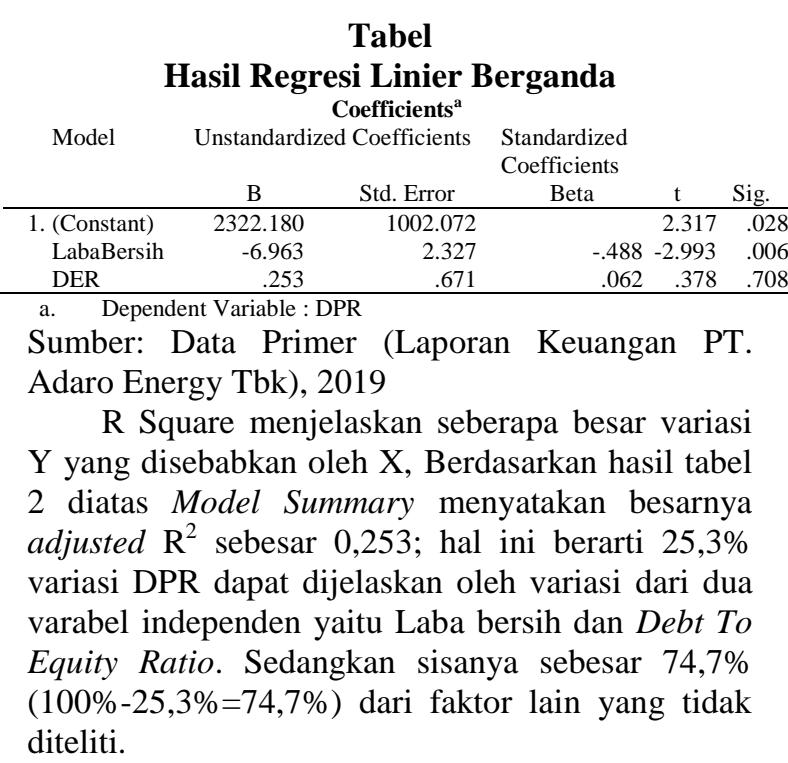

Koefisien Determinasi $\left(\mathbf{R}^{2}\right)$

Tabel

Hasil Koefisien Determinasi Model Summary

\begin{tabular}{ll|r|r|c} 
Model & $\mathrm{R}$ & $\begin{array}{c}\mathrm{R} \\
\text { Square }\end{array}$ & $\begin{array}{c}\text { Adjusted R } \\
\text { Square }\end{array}$ & $\begin{array}{c}\text { Std. Error of } \\
\text { the Estimate }\end{array}$ \\
\hline 1 & $.503^{\mathrm{a}}$ & .253 & .202 & 1788.297741 \\
\hline a. Predictors: (Constant), DER, LabaBersih
\end{tabular}

Sumber: Data Primer (Laporan Keuangan PT. Adaro Energy Tbk), 2019

$\mathrm{R}$ Square menjelaskan seberapa besar variasi Y yang disebabkan oleh X, Berdasarkan hasil tabel 2 diatas Model Summary menyatakan besarnya adjusted $\mathrm{R}^{2}$ sebesar 0,253; hal ini berarti $25,3 \%$ variasi DPR dapat dijelaskan oleh variasi dari dua varabel independen yaitu Laba bersih dan Debt To Equity Ratio. Sedangkan sisanya sebesar $74,7 \%$ $(100 \%-25,3 \%=74,7 \%)$ dari faktor lain yang tidak diteliti.

\section{Koefisien Korelasi Ganda}

\section{Tabel}

Hasil Koefisien Korelasi Ganda

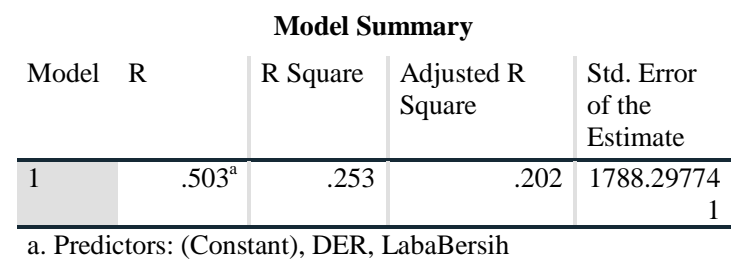

Sumber: Data Primer (Laporan Keuangan PT. Adaro Energy Tbk), 2019

Berdasarkan Tabel diatas diperoleh angka $\mathrm{R}$ sebesar 0,503 Berada pada kategori 0,40-0,599. hal 
ini menunjukkan bahwa terjadinya hubungan yang sedang antara Laba bersih dan Debt To equity Ratio terhadap dividen.

\section{Uji Signifikan Secara Parsial (Uji t)}

Tabel

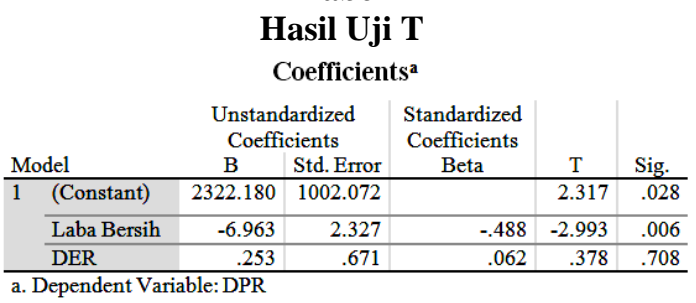

Sumber: Data Primer (Laporan Keuangan PT. Adaro Energy Tbk), 2019

Uji signifikan secara parsial dilakukan untuk mengetahui seberapa besar pengaruh setiap variabel independent terhadap variabel dependent. Hasil uji parsial untuk Laba Bersih nilai sig. $0,006<0,05$,sedangkan nilai $t_{\text {hitung }}$ sebesar $(2,993)$ dan $t_{\text {tabel }} 1,699$. sesuai dengan kriteria pengujian bahwa $t_{\text {hitung }}<t_{\text {tabel }}((2,993)<1,699)$ artinya secara parsial bahwa laba bersih tidak berpengaruh secara positif dan signifikan terhadap dividen.

Sedangkan pada hasil uji parsial untuk Debt to Equity Ratio didapatkan nilai sig. 0,708< 0,05, sedangkan $t_{\text {hitung }} 0,378$ dan $t_{\text {tabel }}$ 1,699. Sesuai dengan kriteria pengujian bahwa $t_{\text {hitung }}<t_{\text {tabel }}$ $(0,378<1,699)$ artinya secara parsial bahwa Debt to Equity Ratio tidak berpengaruh secara positif dan signifikan terhadap dividen.

\section{Uji Signifikan Secara Simultan (Uji F) \\ Tabel \\ Hasil Uji F}

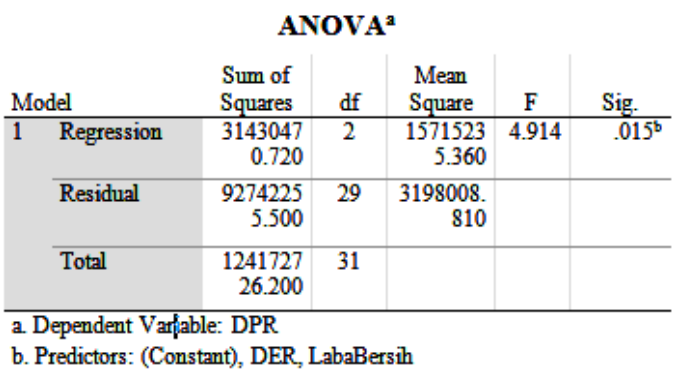

Sumber: Data Primer (Laporan Keuangan PT. Adaro Energy Tbk), 2019

Hasil tabel 5 di atas, hasil uji $F$ yang dilakukan dapat diperoleh nilai $0,015<0,05$; nilai $\mathrm{F}$ hitung 4,914<3,33. Artinya bahwa Laba Bersih dan Debt To Equity Ratio berpengaruh positif dan signifikan terhadap Deviden.

\section{PENUTUP}

\section{Kesimpulan}

Berdasarkan hasil penelitian tentang pengaruh laba bersih dan debt to equity ratio terhadap dividen,diperoleh kesimpulan sebagai berikut:

1. Laba bersih pada PT. Adaro Energy tiap triwulannya berfluktuasi. Laba bersih yang meningkat secara umum disebakan oleh kondisi pendapatan perusahaan yang meningkat.. Hasil uji t yang telah dilakukan, diketahui bahwa laba bersih tidak bepengaruh positif dan signifikan pada dividen PT. Adaro Energy.

2. Pengujian secara parsial menunjukkan bahwa debt to equity ratio tidak berpengaruh positif dan signifikan terhadap dividen PT. Adaro Energy Tbk Periode 2010-2017.

3. Pengujian secara simultan (uji F), menunjukkan bahwa variabel independent Laba Bersih dan Debt To Equity Ratio berpengaruh positif dan signifikan terhadap Dividen pada perusahaan pertambangan PT. Adaro Energy Tbk Periode 2010-2017.

\section{DAFTAR PUSTAKA}

Halim, Abdul., dan Hanafi. (2014) : Analisis Laporan Keuangan. Yogyakarta : UPP STIM YKPN

Hery. (2015) : Analisis Laporan Keuangan. Yogyakarta: PT Grasindo

Fahmi, Irham. (2012) : Analisis Laporan Keuangan. Bandung: Alfabeta

Kasmir. (2012) : Analisis Laporan Keuangan. Jakarta : PT. Raja Grafindo Persada

Sutrisno. (2012) : Manajemen Keuangan. Yogyakarta: Ekonisia

Simammora, Henry. (2013) : Pengantar Akuntansi II. Jakarta : Bumi Aksara

Prihadi, Toto. (2010) : Analisis Laporan Keuangan. Jakarta : Ppm Manajemen

Rudianto. (2012) : Akuntansi Pengantar. Jakarta : Erlangga

Sundjaja. Ridwan S., dan Inge Barlian. (2009) : Manajemen Keuangan 2. Jakarta : Literata Lintas Media

Sugiyono. (2013) : Metode Penelitian Pendidikan Pendekatan Kuantitatif, Kualitatif, dan R\&D. Bandung : Alfabeta

Sujarweni, Wiratna. (2015) : Metodologi Penelitian Bisnis \& Ekonomi. Yogyakarta : Pustakabarupress

Ramli, M.R., dan Arfan. M. (2011) : Pengaruh Laba, Arus Kas Operasi, Arus Kas Bebas, dan Pembayaran Dividen Kas Sebelumnya Terhadap Dividen Kas Yang Diterima Oleh Pemegang Saham. Jurnal Telaah dan Riset Akuntansi, Vol.4, 127-136. 
Utami, N.C. (2016) : Analisis Pengaruh Return On Assets (ROA), Return On Equality (ROE), dan Debt to Equality Ratio (DER) Terhadap Dividend Payout Ratio, 6-7.

Ifada, L.M., dan Kusumadewi, N. (2014) : Pengaruh Laba Bersih, Arus Kas Operasional, Investment Opportunity Set dan Firm Size Terhadap Dividen Kas, Jurnal Dinamika Akuntansi, Vol. 6, 184-185.

Tibrewala, R., Biger, N., dan Gill A. (2010) : Determinants of Divident Payout Ratio : Evidence from United States, The Open Business Journal, Vol.3 , 13.

Annual report adaro energy tbk (Selasa, 18 Desember 2018)

Hartriani, J. 2017. Industri Pertambangan Penopang Perekonomian: Katadata.co.id (Kamis, 20 desember 2018 )

www.idx.com (selasa, 18 Desember 2018)

www.idnfinancials.com (selasa, 18 Desember 2018)

\section{Profil penulis}

1. Septi Utami, S. Ab, Mahasiswa Fakultas Ilmu Administrasi dan Humaniora, Universitas Muhammadiyah Sukabumi.

Email : septiutami945@gmail.com

2. Nor Norisanti, S. Sos., M. Si, Dosen Fakultas Ilmu Administrasi dan Humaniora, Universitas Muhammadiyah Sukabumi.

Email : norisanti.ok@gmail.com

3. Faizal Mulya Z, S. Ab. MA, Dosen Fakultas Ilmu Administrasi dan Humaniora, Universitas Muhammadiyah Sukabumi.

Email : faizal_88@ummi.ac.id 